\title{
Unique and Combined Contribution of Peer Victimization and Maltreatment in Childhood to Young Adults' Anxiety, Depression, and Suicidality: A Cross-Sectional Study
}

Melissa Macalli ( $\sim$ melissa.macalli@u-bordeaux.fr)

University of Bordeaux

Massimiliano Orri

McGill University

Christophe Tzourio

University of Bordeaux

Sylvana M. Côté

University of Montreal

Research Article

Keywords: Peer victimization, child maltreatment, mental health, anxiety, depression, suicidality, young adults

Posted Date: March 1st, 2021

DOI: https://doi.org/10.21203/rs.3.rs-247376/v1

License: (9) This work is licensed under a Creative Commons Attribution 4.0 International License. Read Full License

Version of Record: A version of this preprint was published at BMC Psychiatry on July 14th, 2021. See the published version at https://doi.org/10.1186/s12888-021-03354-4. 


\section{Abstract}

\section{Background}

Child maltreatment and peer victimization are known to be major risk factors for depression and suicidal behavior. Furthermore, child maltreatment increases the risk for victimization by peers. Our objective was to distinguish the contribution of maltreatment by parents and peer victimization to mental health problems in young adulthood. Specifically, we tested whether peer victimization alone or in combination with parental maltreatment before 18 years was associated with anxiety, depression, and suicidal thoughts and behaviors at age 21 years.

\section{Methods}

We used data collected in the i-Share (internet-based students' health research enterprise) study in France from February 2013 to September 2019 ( $N=2271$ participants). We conducted multinomial and binary logistic regression analyses to assess the unique and cumulative contribution of peer victimization and parental maltreatment with anxiety, depression, and suicidality.

\section{Results}

Almost one third of students (28.8\%) reported at least one mental health problem; $29.8 \%$ reported peer victimization only; $7.5 \%$ reported parental maltreatment only; and $10.3 \%$ reported both maltreatment and victimization. In multivariate models, compared to participants who did not experience maltreatment or peer victimization, those who experienced peer victimization only were more likely to present anxiety (aOR: 1.90; 95\% Cl: 1.50-2.40), depression (aOR: 1.95; 95\% Cl: 1.46-2.60), or suicidal ideation without (aOR: 1.62; 95\% Cl: 1.26-2.09) and with attempt (aOR: 2.70; 95\% Cl: 1.51-4.85). Similar associations were observed for those who were maltreated only. Those experiencing both maltreatment and peer victimization were at increased risk for depression (aOR: 2.63; 95\% Cl: 1.79-3.86) and for suicidal ideation with (aOR: 9.19; 95\% Cl: 4.98-16.92) and without attempt (aOR: $2.64 ; 95 \%$ Cl: 1.86-3.76).

\section{Conclusions}

Individual and combined exposure to parental maltreatment and peer victimization in childhood or adolescence was associated with increased risk for anxiety, depression and suicidal behaviors. Peer victimization seems to have a specific role on mental health disorders not otherwise explained by polyvictimization. Since peer victimization is a frequent and evitable child abuse type, the findings have implications for policies to prevent and deal with.

\section{Background}

Child maltreatment and peer victimization in childhood are recognized as important risk factors for mental health problems worldwide [1, 2], including anxiety, depression, and suicidal behavior [3-8]. Child maltreatment includes all types of physical and/or emotional ill-treatment, sexual abuse, neglect, or negligence, which may result in actual or potential harm to the child's health, survival, development or dignity. It is generally perpetrated in the context of a relationship of responsibility, trust or power, as the parent-child relationship [1]. Prevalence estimates vary depending on the country, the definition used, and the assessment methods. In high-income countries, such as UK and USA, prevalence varies from 9-12\% [9-11], although reliable statistics are missing for a large number of countries - including France [12]. Maltreatment by peers (i.e. victimization) during childhood is a multifaceted experience defined as harm caused by peers acting outside of the norms of appropriate conduct [13]. Prevalence estimates of peer victimization vary depending on samples, age cohorts and methodology [14]. According the WHO, across 38 countries or regions, one in three children report being bullied (a form of peer victimization involving an imbalance of power between victim and perpetrator) with a prevalence declining after the age of 11 years old [2].

Strong evidence from previous studies suggest that children experiencing maltreatment are at a higher risk of also being victimized by their peers $[13,15-19]$, and that experiencing both forms of interpersonal violence is associated with increased risk of mental disorder [20] compared to experiencing either maltreatment or peer victimization. Given the link between maltreatment and peer victimization and their long-term effects on mental health outcomes, it is relevant to investigate if peer victimization is 
associated with mental health problems independently from maltreatment. Additionally, failing to take into account maltreatment when investigating the associations between victimization and mental health problems could also obscure of the potential combined effects of victimization on mental health outcomes [21]. Few studies analyzed association of peer victimization and maltreatment alone as well as their cumulative effect on mental health problems.

In the present study, our objective was to distinguish the role of two types of interpersonal violence during childhood on mental health problems in young adulthood. Specifically, we tested whether peer victimization alone or in combination with parental maltreatment before 18 years was associated with anxiety, depression, and suicidal thoughts and behaviors (STB), in a French young adult population at age 21 years.

\section{Methods}

\section{Design, study population and data collection}

Our study sample comprised participants of the ongoing, internet-based, Students 'Health Research Enterprise (i-Share) project, a prospective, population-based study of volunteer students in French-speaking universities and higher education institutions. Enrollment in the i-Share project started in 2013; to be eligible, a student had to be officially registered at a University or higher education institute, at least 18 years of age, able to read and understand French, and provide informed consent for participation. The i-Share enrolment procedure is described elsewhere [22]. The self-administered baseline questionnaire collected sociodemographic characteristics, health information, personal and familial histories, living conditions, and consumptions. For this cross-sectional retrospective study, we used the baseline questionnaire and a complementary questionnaire proposed after the inclusion. A compensation through 20 euros' gift card was given to volunteer students for completing this supplementary questionnaire for whom a part includes childhood adversity questions. For the present study, we used data from a sample of students who were included in the i-Share cohort study between February 2013 and September 2019, who participated in the complementary questionnaire, and for whom data on outcomes were available.

\section{Measures}

\section{Outcome}

Anxiety was measured using the Spielberger State-Trait Anxiety Inventory (STAI-Y) [23]. Range of scores is 20-80, the higher score indicating greater anxiety. Cut offs ranging between 39 to 55 have been suggested to detect clinically significant symptoms for anxiety [24, 25]. In our sample of young adult, we fixed the threshold at the third interquartile. Thus, we included "anxiety" as a binary variable defined as a STAI-Y score of 54 or higher.

Depression was measured using the 9-item Patient Health Questionnaire (PHQ-9), which is a reliable and valid measure of depression severity over the preceding two weeks. A PHQ-9 score of 5 indicated mild depression, 10 moderate depression, 15 moderately severe depression, and 20 severe depression. The 'depression' outcome was a binary variable defined as a PHQ-9 score of 15 or higher, reflecting moderate to severe levels of symptoms [26].

Suicidal thoughts and behaviors. The baseline questionnaire included questions about suicidal thoughts during the last 12 months and lifetime suicide attempts. This variable was categorized in three modalities: "no" included participants who did not reported having any STB (reference group), "suicidal thoughts without attempt" included participants who reported occasional or frequent suicidal thoughts in the last 12 without lifetime suicidal attempt, and "suicidal thoughts and attempt" included participants who reported occasional or frequent suicidal thoughts in the last 12 and lifetime suicidal attempt.

Any mental health problems. Participants with positive scores for either depression, anxiety or STB were coded as having 'any mental health problem' ('yes') and were compared to those who reported none of these problems ('no').

\section{Exposure}

Maltreatment and/or peer victimization were assessed by an adapted version of the Childhood trauma questionnaire (CTQ) [27]. 
Physical and psychological maltreatment were respectively investigated with the following questions: 1) In your childhood or adolescence, did you feel that you were physically abused (beatings, physical punishment...) by your parents? 2) In your childhood or adolescence, have you had the feeling of having been psychologically or emotionally abused (unfair and frequent criticism, mockery, insults, humiliation, etc.) by your parents?

Peer victimization was investigated with the question: In your childhood or adolescence, have you been harassed by other children (such as being regularly insulted or mocked or hit/shocked)? For all these questions, the answers "Never" and "Rarely" were considered as "No" and the answers "Sometimes", "Often", and "Very often" were coded as "Yes". The exposure variable Maltreatment and/or peer victimization was coded as follows: "None" included participants who answered no for any maltreatment and peer victimization, "Peer victimization only" for those who reported only peer victimization without any maltreatment, "Maltreatment only" for those who reported any maltreatment without peer victimization and, "Both" for participants who reported having been maltreated and victimized by peers in childhood and adolescence.

\section{Covariates}

We adjusted for potential confounders relative to childhood adversities identified in the literature as associated to mental health outcomes and exposure variable. Thus, the following self-reported covariates were considered in the analyses: age, gender (male, female), parental divorce or separation (yes, no), parental depression or anxiety history (yes, no), parental alcohol abuse history (yes, no), parental education level (university studies, non-university studies), and difficult economic status in childhood (yes, no).

\section{Statistical analyses}

We first described the overall study sample and according to the categories of the exposure variable (peer victimization only, maltreatment only, both maltreatment and peer victimization, none). Continuous variables are expressed as mean \pm standard error. Categorical variables are described as count and proportion. The Kruskal-Wallis test was used to compare the distributions of age in the groups of exposure variable. Proportions were compared with the Chi-square test.

We measured the association between maltreatment and/or peer victimization and other binary outcomes i.e. "anxiety", "depression" or "any mental health problems" using binary logistic regression analysis, estimating adjusted odds ratios (OR) with $95 \%$ confidence intervals $(\mathrm{Cl})$. As STB is a categorical variable with 3 modalities, multinomial logistic regression models were utilized to assess its relationship with exposure variable. Models convergences were checked. The assumption of linearity of the logit was tested for the continuous variable, age, in each model. The fully adjusted analyses took into account all selected covariates. In each model, to account for missing information for covariates we used MICE (multiple imputation by chained equation) method [28]. We performed 10 imputations, and averaged the variable estimates to produce a mean estimate. Finally, we verified that the relative efficiency of the imputation on each variable was greater than $95 \%$. Then, to test the cumulative effect of both maltreatment and victimization on mental health outcomes compared to peer victimization only and maltreatment only, we conducted the same analyses, changing the reference categories.

Finally, the attributable fraction (AF) was defined as the proportion of each mental health outcome attributable to peer victimization or child maltreatment or both, calculated as follows: $A F=[p *(a O R-1)] /[1+(p *(a O R-1)]$ where $p$ represents the prevalence of the risk factor in our study sample and aOR, the adjusted odds ratio related to the association between the risk factor and the outcome in multivariate models after imputation on missing data.

All analyses were performed using SAS version 9.4. Two-sided $\mathrm{P}$ values of $<0.05$ were considered statistically significant.

\section{Results}

Of the 2476 students that fully completed the baseline and childhood adversity questionnaires, 205 were excluded because they presented missing data for the outcomes. The final study population included 2271 students. Mean age of the participants was 21.0 years $( \pm 2.6)$ and about three quarters were female $(n=1782 ; 78.5 \%)$. Among them, almost one third of students reported at least one mental health problem $(n=654 ; 28.8 \%): 22.4 \%(n=509)$ reported anxiety, $13.6 \%(n=308)$ presented depression symptoms, and $18.3 \%(n=415)$ reported 12-month suicidal ideation without lifetime suicidal attempt and $4.0 \%(n=91)$ with attempt. Table 1 shows the sample characteristics, both overall and categorized by peer victimization, maltreatment and both. 
Almost one third of the sample $(n=677 ; 29.8 \%)$ was exposed to peer victimization only, $7.5 \%(n=170)$ to maltreatment only, and $10.3 \%(n=233)$ to both maltreatment and peer victimization. Participants being maltreated only or both maltreated and victimized by peers were more likely to declare negative family events, such as parental divorce, parental depression history or alcohol abuse history compared to those with none adversity or victimized by peers only.

Table 2 presents the adjusted logistic regression models reporting associations between maltreatment and/or peer-victimization and mental health outcomes after multiple imputation on covariates missing data. Relative to participants who did not experience any maltreatment or peer victimization, those who experienced peer victimization only were at increased odds of anxiety (aOR: 1.90; 95\% Cl: 1.50-2.40), depression (aOR: 1.95; 95\% Cl: 1.46-2.60) and suicidal ideation without (aOR: 1.62; 95\% Cl: 1.26-2.09) and with attempt (aOR: $2.70 ; 95 \% \mathrm{Cl}$ : 1.51-4.85). Similar associations were observed for children exposed to maltreatment only. Participants experiencing both maltreatment and peer victimization were also more likely to present any mental health problems (aOR: 2.94; 95\% Cl: 2.17-4.00), depression (aOR: 2.63; 95\% Cl: 1.79-3.86), or suicidal thoughts with attempt (aOR of 9.19; $95 \% \mathrm{Cl}$ : 4.48-19.92) compared to participants not experiencing maltreatment or peer-victimization.

Additionally, we found an interaction between exposure interpersonal violence and gender $(p<0.0001)$ indicating that girls were at higher risk of STB and boys at higher risk for depression and anxiety when they are exposed to any form of interpersonal violence. However, due to a small number of boys in some exposure categories, we were not able to stratify the analyses by gender.

Table 3 presents the mental health outcomes of participants' exposure to both forms of interpersonal violence compared to those to exposed to peer victimization only or maltreatment only. For children experiencing both maltreatment and peer victimization, associations were not significantly more important than those observed for children exposed to maltreatment only, except for suicidal thoughts with attempts (aOR: $3.65 ; 95 \% \mathrm{Cl}: 1.60-8.33)$. Compared to children exposed to peer victimization only, those experiencing both maltreatment ant peer victimization were more likely to report any mental health problems (aOR: 1.60; $95 \% \mathrm{Cl}$ : 1.17-2.19) and suicidal thoughts with or without attempts but associations with depression and anxiety were not significantly more important.

AFs ranged from $6.0 \%$ to $45.8 \%$ (Table 4 ) in our sample study. We observed that for the outcome any mental health disorders, the AF for peer victimization only was larger than the AF for maltreatment only. The AFs for peer victimization only are closer to those for both maltreated and victimized than those for maltreatment only. For example, $20.0 \%$ of any mental health disorder and $15.6 \%$ of suicidal ideation without attempt could be attributed to peer victimization, while the corresponding AFs for maltreatment were $8.1 \%$ and $7.5 \%$ and those for both maltreatment and peer victimization were $16.7 \%$ and $14.5 \%$.

\section{Discussion}

\section{Main findings and interpretation}

In this cross-sectional study of 2271 French young adults, we found an increased risk of mental health problems in young adulthood including anxiety, depression and STB in people who were victimized by peers whether or not they were exposed to parental child maltreatment. Overall, for children experiencing both maltreatment and peer victimization, associations were not significantly more important than for those exposed to either maltreatment or peer victimization - except for suicidal thoughts with attempts.

The prevalence rates of peer victimization and maltreatment in our sample are close to those estimated in previous studies [2, 911]. Peer victimization only is highly prevalent as it concerns one third of the sample which explain large AFs comparable to those of combined maltreatment and peer victimization.

Our results suggest the important independent role of peer victimization and are in line with other studies [29]. A longitudinal study highlighted that being the victim of peer victimization has an independent effect on young adults' mental health, and being victimized by peers had worse long-term adverse effects on young adults' mental health than being maltreated [30]. Previous research also shows the important effect of peer victimization on mental health problems, as children experiencing bullying victimization had similar risk of negative mental health outcomes than children who were placed in public or substitute care [31]. 
Studies showed that parental support and positive familial relationship in childhood have long term positive effects on adult mental health and provide a crucial foundation for social interactions [32,33]. Thus, parental maltreatment in childhood increase the likelihood of children to be victimized by their peers owing to impairment of children' emotional regulation skills [34]. Indeed, attachment theory, highlights how children internalize aspects of caregiving relationships and this experience impair later peer interactions [35]. It is worth noting that maltreatment and peer victimization refer to experiences of interpersonal violence occurring in two different environmental contexts - the home and the school, respectively. It is possible that some individuals who experience maltreatment in the home environment consider themselves to be victims regardless of the context. However, our results show that associations between peer victimization and mental health outcomes were not fully explained by exposure to both types of interpersonal violence. Moreover, these associations remain significant even after controlling for important familial variables. This stresses the importance of interpersonal experiences occurring outside the family sphere, and with peers specifically, which seem to have a specific role on mental health. As children grow-up, peer interactions became increasingly important. Repetitive verbal or physical harassment or exclusion from peers might have long term effects independently of other childhood adversity, modifying stress responses [36]. Furthermore, our findings suggest than cumulative maltreatment effects may be at least partly due to being victimized. Thus, future studies of maltreatment should also take into account peer victimization.

\section{Strengths and limitations}

The present study had some important strengths, including large and contemporaneous sample of French young adults, a study population never investigated on this subject. We also note the consistency of our results with previous studies, and the ability to adjust for a range of confounders due to the wide range of available variables. Depression and anxiety were measured using validated scales with excellent psychometric properties and exposures were measured with an adapted version of the CTQ. Furthermore, a significant association of peer victimization only was found for each mental health outcome, providing consistent results. Despite these strengths, several limitations should be considered when interpreting the results. First, it was a crosssectional analysis; therefore, we could not strictly separate the timing of exposure, outcome, and covariates and no causality could be inferred between exposure and mental health outcomes. Second, the voluntary participation of students at baseline and in the supplementary questionnaire may have introduced a self-selection bias, although it is difficult to see how this potential bias could have influenced the results. Third, the information was self-reported, which could lead to an information bias, particularly memory bias as exposure assessment was retrospective. Fourth, there is an over-representation of women in our sample compared to the $56 \%$ of female students in France and our results suggest differences between gender according mental health problems and maltreatment exposure. Finally, we could not investigate the age of onset of peer victimization and maltreatment and the type of peer victimization.

\section{Conclusions}

In a large sample of young adults, individual and combined exposure to parental maltreatment and peer victimization in childhood or adolescence was associated with increased risk for mental health problems. Peer victimization seems to have a specific role on mental health problems over and beyond the role of the exposure to maltreatment. Since peer victimization is frequent but preventable, these findings stress the importance of coordinating the responses of schools, teachers, health services and public policies to address this widespread problem.

\section{Abbreviations}

AF: Attributable fraction; aOR: Adjusted odds ratio; Cl: Confidence interval; i-Share: Internet-based Students' Health Research Enterprise; MICE: Multiple imputation by chained equation; OR: Odds ratio; SD: Standard deviation; UK: United Kingdom; USA: United States of America; WHO: World Health Organization.

\section{Declarations}

\section{Acknowledgements}


The authors are grateful to the coordinating team of the i-Share project for their assistance in setting up and collecting data. In particular, we would like to thank: Clothilde Pollet, Edwige Pereira, Marie Mougin, Elena Milesi, Aude Pouymayou and Garance Perret. We thank all the students that participated in the i-Share study.

\section{Authors' contributions}

$M M, C T$, and SMC designed the study. MM conducted the statistical analysis. MM, MO, CT and SMC wrote the first draft of the manuscript. All co-authors had full access to the data, read, revised, and approved the final manuscript.

\section{Funding}

The preparation and initiation of the i-Share project was funded by the program 'Invest for the future' (reference ANR-10-COHO05). The i-Share project is currently supported by an unrestricted grant of the Nouvelle-Aquitaine Regional Council (Conseil Régional Nouvelle-Aquitaine) (grant $\mathrm{N}^{\circ}$ 4370420) and by the Bordeaux 'Initiatives d'excellence' (IdEx) program of the University of Bordeaux (ANR-10-IDEX-03-02). M.Macalli was supported by a PhD grant of the Nouvelle-Aquitaine Regional Council (grant $\mathrm{N}^{\circ} 17$ EURE-0019) and by the PhD Digital Public Health Graduate School Program supported within the framework of the PIA3 (Investment for the Future) (project reference: 17-EURE-0019). We thank Public Health France (Santé Publique France), the National Cancer Institute (INCA), and the Medical Research Foundation (FRM). The funding sponsor played no role in the design of the

study; in the collection, analyses, or interpretation of data; in writing the manuscript; or in the decision to publish the results.

\section{Availability of data and materials}

The datasets used and/or analyzed during the current study are available from the corresponding author on reasonable request.

\section{Ethics approval and consent to participate}

The i-Share project was approved by the "Commission nationale de l'informatique et des libertés" (National Commission of Informatics and Liberties, Reference DR-2013-019). All methods were carried out in accordance with relevant guidelines and regulations. Informed consent was obtained from all participants. Students were informed on the nature and purpose of the study and provided on-line consent.

\section{Consent for publication}

Not applicable

\section{Competing interests}

The authors declare that they have no competing interests.

\section{Author details}

Melissa Macalli, ${ }^{1}$ PhD student; Massimiliano Orri, ${ }^{1,2}$ PhD; Christophe Tzourio, ${ }^{1}$ MD, PhD; Sylvana M. Côté, ${ }^{1,3}$ PhD;

${ }^{1}$ University of Bordeaux, Inserm, Bordeaux Population Health Research Center, UMR 1219, F-33000 Bordeaux, France.

${ }^{2}$ McGill Group for Suicide Studies, Douglas Mental Health University Institute and Department of Psychiatry, McGill University, Montreal, QC, Canada.

${ }^{3}$ School of Public Health, University of Montreal, QC H3T 1J4, Canada.

\section{References}

1. World Health Organization WHO. Child maltreatment. https://www.who.int/news-room/fact-sheets/detail/child-maltreatment (2020). Accessed 9 Dec 2020. 
2. World Health Organization WHO. Social determinants of health and well-being among young people. Health Behaviour in School-aged Children (HBSC) study: international report from the 2009/2010 survey.

https://www.euro.who.int/en/publications/abstracts/social-determinants-of-health-and-well-being-among-young-people.health-behaviour-in-school-aged-children-hbsc-study (2012). Accessed 9 Dec 2020.

3. Angelakis I, Austin JL, Gooding P. Association of Childhood Maltreatment With Suicide Behaviors Among Young People: A Systematic Review and Meta-analysis. JAMA Netw Open. 2020; doi: 10.1001/jamanetworkopen.2020.12563.

4. Norman RE, Byambaa M, De R, Butchart A, Scott J, Vos T. The long-term health consequences of child physical abuse, emotional abuse, and neglect: a systematic review and meta-analysis. PLoS Med. 2012; doi: 10.1371/journal.pmed.1001349.

5. Stapinski LA, Bowes L,Wolke D, et al. Peer victimization during adolescence and risk for anxiety disorders in adulthood: a prospective cohort study. Depress Anxiety. 2014; doi:10.1002/da.22270.

6. Sourander A, Jensen P, Rönning JA, et al. What is the early adulthood outcome of boys who bully or are bullied in childhood? the Finnish "From a Boy to a Man" study. Pediatrics. 2007; doi: 10.1542/peds.2006-2704.

7. Klomek AB, Sourander A, Niemelä S, Kumpulainen K, Piha J, Tamminen T, Almqvist F, Gould MS. Childhood bullying behaviors as a risk for suicide attempts and completed suicides: a population-based birth cohort study. J Am Acad Child Adolesc Psychiatry. 2009 Mar;48(3):254-261. doi: 10.1097/CHI.0b013e318196b91f.

8. Holt MK, Vivolo-Kantor AM, Polanin JR, Holland KM, DeGue S, Matjasko JL, Wolfe M, Reid G. Bullying and suicidal ideation and behaviors: a meta-analysis. Pediatrics. 2015; doi: 10.1542/peds.2014-1864.

9. Gilbert R, Widom CS, Browne K, Fergusson D, Webb E, Janson S. Burden and consequences of child maltreatment in highincome countries. Lancet. 2009; doi: 10.1016/S0140-6736(08)61706-7.

10. Wildeman C, Emanuel N, Leventhal JM, Putnam-Hornstein E, Waldfogel J, Lee H. The prevalence of confirmed maltreatment among US children, 2004 to 2011. JAMA Pediatr. 2014; doi: 10.1001/jamapediatrics.2014.410.

11. Radford L, Corral S, Bradley C, et al. Child abuse and neglect in the UK today. London: National Society for the Prevention to Cruelty to Children, 2011.

12. Tursz A. La maltraitance des enfants en France - Prendre enfin la mesure de son poids individuel et sociétal [Child abuse and neglect in France. Finally recognize its individual and societal impact]. Med Sci (Paris). 2017 ; French. doi:

$10.1051 /$ medsci/20173310001.

13. Oncioiu SI, Orri M, Boivin M, Geoffroy MC, Arseneault L, Brendgen M, Vitaro F, Navarro MC, Galéra C, Tremblay RE, Côté SM. Early Childhood Factors Associated With Peer Victimization Trajectories From 6 to 17 Years of Age. Pediatrics. 2020; doi: 10.1542/peds.2019-2654.

14. Husky MM, Delbasty E, Bitfoi A, Carta MG, Goelitz D, Koç C, Lesinskiene S, Mihova Z, Otten R, Kovess-Masfety V. Bullying involvement and self-reported mental health in elementary school children across Europe. Child Abuse Negl. 2020; doi: 10.1016/j.chiabu.2020.104601.

15. Lereya ST, Samara M, Wolke D. Parenting behavior and the risk of becoming a victim and a bully/victim: a meta-analysis study. Child Abuse Negl. 2013; doi: 10.1016/j.chiabu.2013.03.001.

16. Radford L, Corral S, Bradley C, Fisher HL. The prevalence and impact of child maltreatment and other types of victimization in the UK: findings from a population survey of caregivers, children and young people and young adults. Child Abuse Negl. 2013; doi: 10.1016/j.chiabu.2013.02.004.

17. Ssenyonga J, Magoba Muwonge C, Hecker T. Prevalence of family violence and mental health and their relation to peer victimization: A representative study of adolescent students in Southwestern Uganda. Child Abuse Negl. 2019; doi: 10.1016/j.chiabu.2019.104194.

18. Turner HA, Finkelhor D, Ormrod R. Poly-victimization in a national sample of children and youth. Am J Prev Med. 2010; doi: 10.1016/j.amepre.2009.11.012.

19. Wang Q. Association of Childhood Intrafamilial Aggression and Childhood Peer Bullying With Adult Depressive Symptoms in China. JAMA Netw Open. 2020; doi: 10.1001/jamanetworkopen.2020.12557.

20. Holt MK, Finkelhor D, Kantor GK. Multiple victimization experiences of urban elementary school students: associations with psychosocial functioning and academic performance. Child Abuse Negl. 2007; doi: 10.1016/j.chiabu.2006.12.006. 
21. Finkelhor D, Ormrod RK, Turner HA. Poly-victimization: a neglected component in child victimization. Child Abuse Negl. 2007; doi: 10.1016/j.chiabu.2006.06.008.

22. Macalli M, Tournier M, Galéra C, Montagni I, Soumare A, Côté SM, Tzourio C. Perceived parental support in childhood and adolescence and suicidal ideation in young adults: a cross-sectional analysis of the i-Share study. BMC Psychiatry. 2018; doi: 10.1186/s12888-018-1957-7.

23. Laux L, Glanzmann P, Schaffner P, Spielberger C. Das State-Trait Angstinventar: STAl. Weinheim: Beltz Test GmbH 1981.

24. Wiglusz MS, Landowski J, Cubała WJ. Psychometric properties and diagnostic utility of the State-Trait Anxiety Inventory in epilepsy with and without comorbid anxiety disorder. Epilepsy Behav. 2019; doi: 10.1016/j.yebeh.2019.01.005.

25. Julian LJ. Measures of anxiety: State-Trait Anxiety Inventory (STAI), Beck Anxiety Inventory (BAI), and Hospital Anxiety and Depression Scale-Anxiety (HADS-A). Arthritis Care Res (Hoboken). 2011; doi:10.1002/acr.20561.

26. Kroenke K, Spitzer RL, Williams JB. The PHQ-9: validity of a brief depression severity measure. J Gen Intern Med. 2001; doi: 10.1046/j.1525-1497.2001. 016009606.x.

27. Paquette D, Laporte L, Bigras M, Zoccolillo M. Validation of the French version of the CTQ and prevalence of the history of maltreatment. Sante Ment Que. 2004; doi: 10.7202/008831ar.

28. Van Buuren, S. Multiple imputation of discrete and continuous data by fully conditional specification. Stat. Methods Med. Res 2007; doi:10.1177/0962280206074463.

29. Copeland WE, Wolke D, Angold A, Costello EJ. Adult psychiatric outcomes of bullying and being bullied by peers in childhood and adolescence. JAMA Psychiatry. 2013; doi: 10.1001/jamapsychiatry.2013.504.

30. Lereya ST, Copeland WE, Costello EJ, Wolke D. Adult mental health consequences of peer bullying and maltreatment in childhood: two cohorts in two countries. Lancet Psychiatry. 2015; doi: 10.1016/S2215-0366(15)00165-0.

31. Takizawa R, Maughan B, Arseneault L. Adult health outcomes of childhood bullying victimization: evidence from a fivedecade longitudinal British birth cohort. Am J Psychiatry. 2014; doi: 10.1176/appi.ajp.2014.13101401.

32. Macalli M, Côté S, Tzourio C. Perceived parental support in childhood and adolescence as a tool for mental health screening in students: A longitudinal study in the i-Share cohort. J Affect Disord. 2020; doi: 10.1016/j.jad.2020.02.009

33. Cowan PA, Cowan CP, Cohn DA, Pearson JL. Parents' attachment histories and children's externalizing and internalizing behaviors: exploring family systems models of linkage. J Consult Clin Psychol. 1996; doi: 10.1037//0022-006x.64.1.53.

34. Shields A, Cicchetti D. Parental maltreatment and emotion dysregulation as risk factors for bullying and victimization in middle childhood. J Clin Child Psychol. 2001; doi:10.1207/S15374424JCCP3003_7.

35. Zeanah $\mathrm{CH}$, Zeanah PD. Intergenerational transmission of maltreatment: insights from attachment theory and research. Psychiatry. 1989; doi: 10.1080/00332747.1989.11024442.

36. Copeland WE, Wolke D, Lereya ST, Shanahan L, Worthman C, Costello EJ. Childhood bullying involvement predicts low-grade systemic inflammation into adulthood. Proc Natl Acad Sci U S A. 2014; doi: 10.1073/pnas.1323641111.

\section{Tables}

Table 1 Characteristics of the study sample overall and according to child maltreatment or peer victimization. 


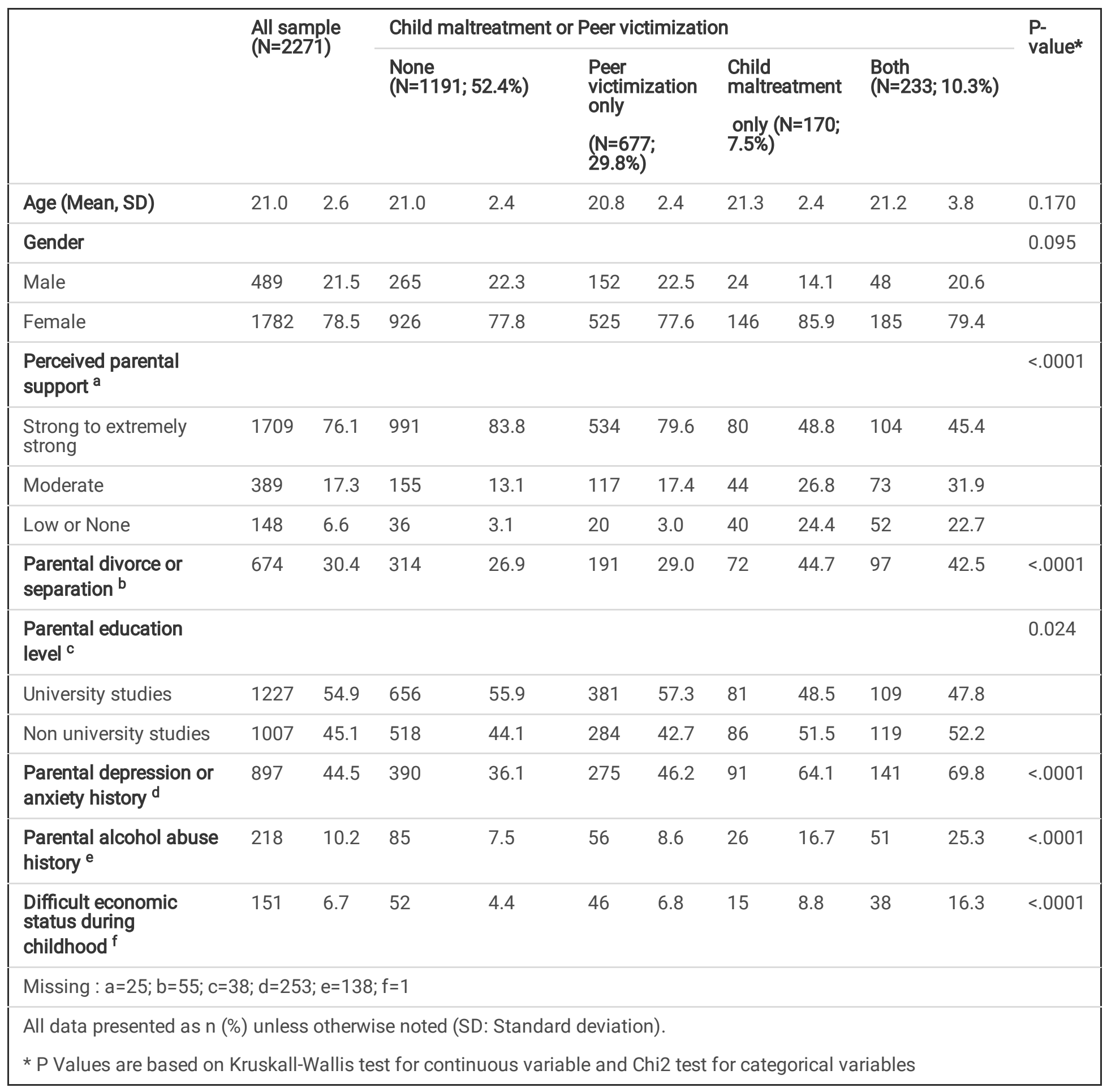

Table 2 Associations between mental health outcomes and child maltreatment and/or peer victimization ( $\mathrm{N}=2271)$. 


\begin{tabular}{|c|c|c|c|c|c|c|c|c|c|c|}
\hline \multirow{2}{*}{$\begin{array}{l}\text { Maltreatment } \\
\text { or } \\
\text { Peer } \\
\text { victimization }\end{array}$} & \multicolumn{2}{|c|}{$\begin{array}{l}\text { Suicidal thoughts } \\
\text { without attempt }\end{array}$} & \multicolumn{2}{|c|}{$\begin{array}{l}\text { Suicidal thoughts } \\
\text { with attempt }\end{array}$} & \multicolumn{2}{|c|}{ Depression } & \multicolumn{2}{|c|}{ Anxiety } & \multicolumn{2}{|c|}{$\begin{array}{l}\text { Any mental health } \\
\text { problems }\end{array}$} \\
\hline & $\mathbf{n}$ & OR $(95 \% \mathrm{Cl})$ & $\mathbf{n}$ & OR $(95 \% \mathrm{Cl})$ & $\mathbf{n}$ & OR $(95 \% \mathrm{Cl})$ & $\mathbf{n}$ & OR $(95 \% \mathrm{Cl})$ & $\mathbf{n}$ & OR $(95 \% \mathrm{Cl})$ \\
\hline None & 162 & 1(reference) & 20 & 1(reference) & 109 & 1 (reference) & 188 & 1 (reference) & 246 & 1 (reference) \\
\hline $\begin{array}{l}\text { Peer } \\
\text { victimization } \\
\text { only }\end{array}$ & 140 & $\begin{array}{l}1.62(1.26- \\
2.09)\end{array}$ & 29 & $\begin{array}{l}2.70(1.51- \\
4.85)\end{array}$ & 112 & $\begin{array}{l}1.95(1.46- \\
2.60)\end{array}$ & 183 & $\begin{array}{l}1.90(1.50- \\
2.40)\end{array}$ & 225 & $\begin{array}{l}1.84(1.48- \\
2.29)\end{array}$ \\
\hline $\begin{array}{l}\text { Maltreatment } \\
\text { only }\end{array}$ & 45 & $\begin{array}{l}2.08(1.41- \\
3.07)\end{array}$ & 8 & $\begin{array}{l}2.54(1.08- \\
6.00)\end{array}$ & 31 & $\begin{array}{l}1.85(1.18- \\
2.91)\end{array}$ & 54 & $\begin{array}{l}2.16(1.49- \\
3.13)\end{array}$ & 69 & $\begin{array}{l}2.18(1.54- \\
3.09)\end{array}$ \\
\hline Both & 68 & $\begin{array}{l}2.64(1.86- \\
3.76)\end{array}$ & 34 & $\begin{array}{l}9.19(4.98- \\
16.92)\end{array}$ & 56 & $\begin{array}{l}2.63(1.79- \\
3.86)\end{array}$ & 84 & $\begin{array}{l}2.62(1.89- \\
3.64)\end{array}$ & 114 & $\begin{array}{l}2.94(2.17- \\
4.00)\end{array}$ \\
\hline \multicolumn{11}{|c|}{ OR: odds ratio, Cl: confidence interval } \\
\hline
\end{tabular}

Table 3 Associations between mental health outcomes and child maltreatment only or peer victimization only vs both maltreatment and peer victimization.

\begin{tabular}{|c|c|c|c|c|c|c|c|c|c|c|}
\hline \multirow{2}{*}{$\begin{array}{l}\text { Maltreatment } \\
\text { or } \\
\text { Peer } \\
\text { victimization } \\
\text { vs Both }\end{array}$} & \multicolumn{2}{|c|}{$\begin{array}{l}\text { Suicidal thoughts } \\
\text { without attempt }\end{array}$} & \multicolumn{2}{|c|}{$\begin{array}{l}\text { Suicidal thoughts } \\
\text { with attempt }\end{array}$} & \multicolumn{2}{|c|}{ Depression } & \multicolumn{2}{|c|}{ Anxiety } & \multicolumn{2}{|c|}{$\begin{array}{l}\text { Any mental health } \\
\text { problems }\end{array}$} \\
\hline & $\mathbf{n}$ & OR $(95 \% \mathrm{Cl})$ & $\mathrm{n}$ & OR $(95 \% \mathrm{Cl})$ & $\mathbf{n}$ & OR (95\% Cl) & $\mathbf{n}$ & OR (95\% Cl) & $\mathbf{n}$ & OR $(95 \% \mathrm{Cl})$ \\
\hline \multicolumn{11}{|l|}{$\begin{array}{l}\text { Model } 1 \\
(\mathrm{~N}=910)\end{array}$} \\
\hline $\begin{array}{l}\text { Peer } \\
\text { victimization } \\
\text { only }\end{array}$ & 140 & 1 (reference) & 29 & 1(reference) & 112 & 1(reference) & 183 & 1 (reference) & 225 & 1 (reference) \\
\hline Both & 68 & $\begin{array}{l}1.64(1.18- \\
2.35)\end{array}$ & 34 & $\begin{array}{l}3.41(1.95- \\
5.97)\end{array}$ & 56 & $\begin{array}{l}1.35(0.92- \\
1.98)\end{array}$ & 84 & $\begin{array}{l}1.38(0.99- \\
1.93)\end{array}$ & 114 & $\begin{array}{l}1.60(1.17- \\
2.19)\end{array}$ \\
\hline \multicolumn{11}{|l|}{$\begin{array}{l}\text { Model } 2 \\
(\mathrm{~N}=403)\end{array}$} \\
\hline $\begin{array}{l}\text { Maltreatment } \\
\text { only }\end{array}$ & 45 & 1 (reference) & 8 & 1 (reference) & 31 & 1 (reference) & 54 & 1 (reference) & 69 & 1 (reference) \\
\hline Both & 68 & $\begin{array}{l}1.28(0.81- \\
2.03)\end{array}$ & 34 & $\begin{array}{l}3.65(1.60- \\
8.33)\end{array}$ & 56 & $\begin{array}{l}1.41(0.86- \\
2.35)\end{array}$ & 84 & $\begin{array}{l}1.22(0.79- \\
1.87)\end{array}$ & 114 & $\begin{array}{l}1.35(0.90- \\
2.03)\end{array}$ \\
\hline \multicolumn{11}{|c|}{ OR: odds ratio, Cl: confidence interval } \\
\hline
\end{tabular}

Table 4 Attributable fractions (\%) of child maltreatment and/or peer victimization for mental health outcomes. 


\begin{tabular}{|llllll|}
\hline & $\begin{array}{l}\text { Suicidal thoughts without } \\
\text { attempt }\end{array}$ & $\begin{array}{l}\text { Suicidal thoughts with } \\
\text { attempt }\end{array}$ & Depression & Anxiety & $\begin{array}{l}\text { Any mental health } \\
\text { problems }\end{array}$ \\
\hline $\begin{array}{l}\text { Peer victimization } \\
\text { only }\end{array}$ & 15.6 & 33.6 & 22.0 & 21.1 & 20.0 \\
\hline Maltreatment only & 7.5 & 10.4 & 6.0 & 8.0 & 8.1 \\
\hline Both & 14.5 & 45.8 & 14.4 & 14.3 & 16.7 \\
\hline
\end{tabular}

